\title{
Matrix-immobilized yeast for large-scale production of recombinant human lactoferrin $\dagger$
}

Cite this: Med. Chem. Commun., $2015,6,486$

Received 2nd December 2014, Accepted 16th February 2015

DOI: $10.1039 / c 4 m d 00537 f$

www.rsc.org/medchemcomm

\author{
Chun Loong Ho, In Young Hwang, Kathy Lohł and Matthew Wook Chang:*
}

\begin{abstract}
An improved method of producing and purifying large quantities of recombinant human lactoferrin (hLF) in rich culture medium is demonstrated. The host yeast cells were immobilized using macroporous microencapsulation and introduced to a rich medium to facilitate lactoferrin production. The induced and constitutive expression of lactoferrin using the macroporous microencapsulated yeast resulted in a titer of $18.6 \mathrm{mg} \mathrm{l}^{-1}$, which is a 9-fold increase from the previously reported highest titer. It was further demonstrated that the macroporous encapsulation circumvented the use of selection pressure to maintain cellular plasmids at a high copy number. The purified hLF exhibited anti-bacterial properties and inhibitory activity against various breast, gastric and colorectal cancer cell lines.
\end{abstract}

\section{Introduction}

Lactoferrin is a transferrin-class protein known to confer various health beneficial properties, including anti-microbial, anti-parasite and anti-cancer activities. These attributes are credited to the ability of the protein to sequester metal ions and recruit immune-related cytokines. ${ }^{1,2}$ The lactoferrin protein is used in tandem as a second-line therapeutic agent with other treatments to reduce the drug side-effects and improve the recovery of the patients. ${ }^{3}$ This glycoprotein, which averages about $80 \mathrm{kDa}$ in size, mainly sequesters ferric ions, but it is also known to bind to DNA and other metabolites and divalent ions at a lesser capacity. ${ }^{1 c}$ The protein structure has a double lobe at the $\mathrm{N}$ - and $\mathrm{C}$-termini that can each bind to a single $\mathrm{Fe}^{3+}$ ion (Fig. 1A and B). This class of protein reportedly has stronger binding affinity in a lower $\mathrm{pH}$ environment. ${ }^{4}$ The tryptic- and peptic-digested lactoferrin fragments are found to show higher efficacy in conferring various healthbenefiting properties. ${ }^{5}$ These properties are contributed by various conserved sequences hidden in the lactoferrin tertiary structure. The improved efficacy is attributed to the exposure of these conserved residues upon tryptic and peptic digestion. ${ }^{6}$ One such example could be seen at the conserved antifungal sequence found in the $\mathrm{N}$-terminus lobe of various lactoferrins (Fig. S1). ${ }^{7}$ Prior studies have indicated that the

Department of Biochemistry, Yong Loo Lin School of Medicine, and Synthetic Biology Research Program, Life Sciences Institute, National University of Singapore, 28 Medical Drive, Singapore 117456. E-mail: bchcmw@nus.edu.sg $\dagger$ Electronic supplementary information (ESI) available. See DOI: 10.1039/ c4md00537f

\$ Author contribution: H. C. L. and M. W. C. conceived and designed the project. H. C. L. performed the experiments. K. L. contributed in gene cloning. H. C. L., I. Y. H. and M. W. C. conducted data analysis and interpretation and wrote the manuscript. M. W. C. supervised the project. glycosylation of the lactoferrin protein results in higher activity and tolerance to low pH values. ${ }^{1 b}$ It has also been shown that human lactoferrin (hLF) confers a higher modulated

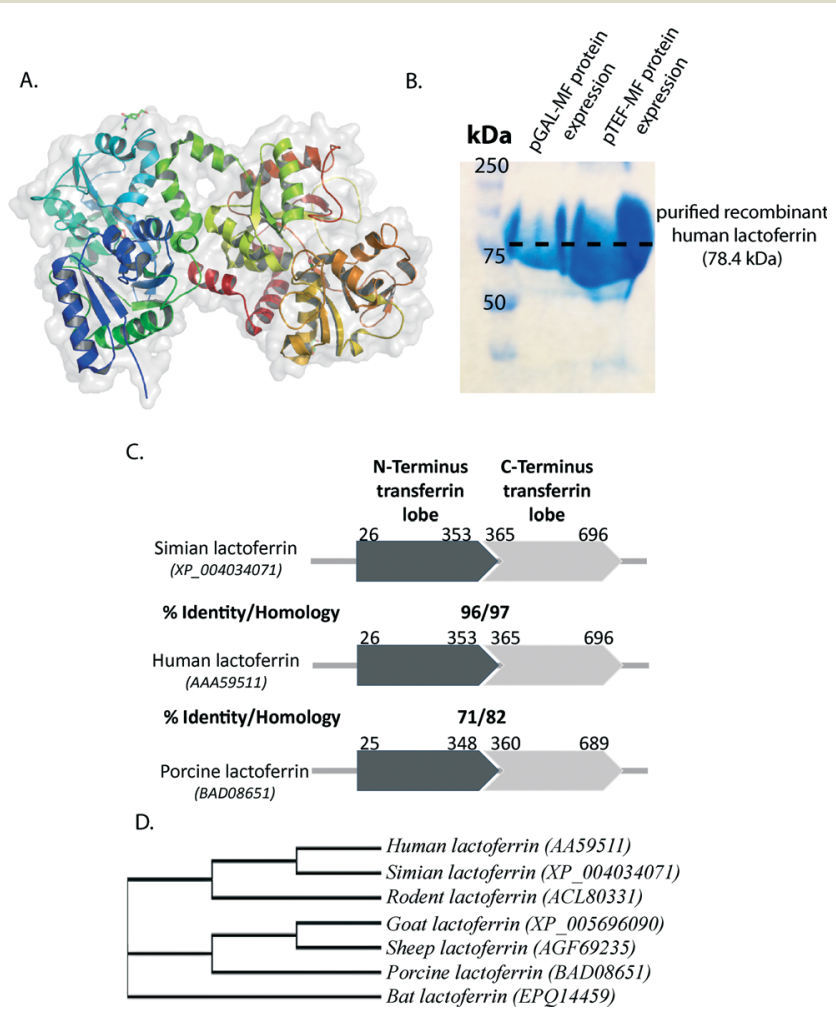

Fig. 1 A. Crystal structure of hLF (PDB ID: 2BJJ) (N- to C-terminus is indicated from the blue to red colour coding). B. Saccharomyces cerevisiae expression of recombinant hLF. C. The sequence identity/ homology of hLF against simian and porcine lactoferrin. D. A phylogeny tree of lactoferrins from various sources. 
response towards human-related diseases than bovine-derived lactoferrin, which was demonstrated in the studies of sepsis and necrotizing enterocolitis prevention, ${ }^{8}$ and anti-viral activity via interaction with heparin sulphate (HS). ${ }^{9}$ In addition, the over-dosage of milk-purified bovine lactoferrin causes diarrhoea, skin rashes, decreased appetite, fatigue, chills and constipation. ${ }^{10}$ The recombinant hLF gene shows higher than 90\% sequence identity to other lactoferrins from primates such as Pongo abelii, Macaca fascicularis, Chlorocebus sabaeus, and Gorilla gorilla gorilla (Fig. 1C), whilst showing an average of above $70 \%$ sequence identity to other lactoferrins (Fig. 1D).

Despite these health-benefiting properties of lactoferrin, the price of purified lactoferrin still remains high, thus prompting various studies to produce and/or supplement food with lactoferrin. The purification of hLF from human milk colostrum is not feasible because it is not possible to acquire high quantities of human-derived milk. Thus, the production of hLF in other hosts is a viable option to increase the supply. Industrial approaches to mass produce hLF include engineered bacteria, yeast, fungi, insect cells, mammalian cells and transgenic plants. ${ }^{11}$ Despite bacteria being a favoured host for large-scale protein expression, human lactoferrin produced with prokaryotic hosts often show lower efficacy because the expression requires posttranslational glycosylation. These glycosylation sites are mainly found on the protein surface. Furthermore, lactoferrins produced in conventional plant, mammalian or insect host cells usually produce holo-lactoferrin that is almost completely bound to the ferric ions present in the cytosol of the host cells. ${ }^{12}$ Yeast cells can produce glycosylated apo-lactoferrin. The expression of lactoferrin using Pichia pastoris was shown to produce lactoferrin at a titer of $115 \mathrm{mg} \mathrm{l}^{-1}$. However, the fermentation process involves incubation for 9 days using alcohol induction and could affect the stability of secreted proteins in the media. ${ }^{13}$ On the other hand, the use of Saccharomyces cerevisiae is reported to result in a low expression titer of $2.0 \mathrm{mg} \mathrm{l}^{-1} .^{14}$ Thus, in this study, to increase the titer of lactoferrin, we engineered the budding yeast Saccharomyces cerevisiae BY4741 to express and secrete recombinant hLF. To further improve the titer and the purity of the expressed protein, the host cells were immobilized in a gel matrix and their performance was evaluated in comparison to the cells in the liquid culture. We further assessed the performance of two different microencapsulation techniques that were previously used in eukaryotic cell protein expression. The first method is by encapsulating the cells in 3 layers containing alginate-poly-Llysine-alginate. This alginate-poly-L-lysine-alginate (APA) resin is commonly used for protein expression in eukaryotic cells such as recombinant Chinese hamster ovarian cells, ${ }^{15}$ mesenchymal stem cells ${ }^{16}$ and NIH3T-NGF cells. ${ }^{17}$ The second method employs macroporous microencapsulation, which uses a mixture of alginate and agarose to produce porous microcapsules that enable efficient medium transfer and protein secretion into the surrounding medium. This encapsulation method was previously used to facilitate protein expression in pig islet cells to treat type 1 diabetes. ${ }^{18}$ These immobilized yeast cells were evaluated by observing the titer of the expressed protein over a series of batch-culture fermentation.

Herein, we report an improved protocol to express and purify secreted hLF using matrix-immobilized recombinant yeast cultured in a liquid medium for batch culture fermentation. The purified protein was characterized for its antimicrobial activity and anti-cancer activity against breast, gastric and colorectal cancer cell-lines.

\section{Results and discussion}

Our transformed yeast expression showed the highest titer of secreted recombinant hLF, about 9-fold increase in expression levels from $2.0 \mathrm{mg} \mathrm{l^{-1 }}$ previously reported in $S$. cerevisiae. ${ }^{14}$ A total of $18.6 \mathrm{mg}$ and $15.3 \mathrm{mg}$ of soluble active hLF were purified from each litre of the rich liquid culture using constitutive and induced protein expression (Fig. 1B). Validation of recombinant hLF protein by size exclusion chromatography indicated that the protein was in the correct monomeric state.

The hLF expression using matrix-immobilized yeast indicated that the macroporous microencapsulation of the recombinant yeast was the most suitable method for immobilized yeast cell-based protein expression. The immobilized yeast cells in both the APA and the macroporous matrices showed that the total wet mass of the spun down matrix was consistent throughout 4 batch cycles. This indicates no significant cell division during the course of incubation, thus addressing the issue of a potential plasmid loss upon cellular replication. The lowered primary metabolism due to reduced cell division could further encourage protein expression. $^{19}$ The hLF expression using APA microencapsulated yeast cells might not be suitable because the yield of purified hLF from the first batch was less than half the amount purified from free cell expression. The second batch culture of purified hLF using APA microencapsulation dropped to below $1 \mathrm{mg} \mathrm{l}^{-1}$ (Fig. 2A and C). However, the expression of hLF in macroporous microencapsulation immobilized yeast retained the expression levels close to the free cell expression. Furthermore, the macroporous microencapsulated yeast could be reused with an acceptable titer for up to 3 batch cycles (approx. 10 days). This observation was consistent in the titer level from the induced and constitutive expression of secreted lactoferrin (Fig. 2B and D). The reduced expression observed with the APA microencapsulation technique might result from the presence of poly-L-lysine in the resin. That is, $\varepsilon$-poly-L-lysine exhibits antimicrobial activity against bacteria, fungi and yeast at high concentrations that might negatively impact the yeast cells in the immobilized matrix. ${ }^{20}$ Additionally, poly-L-lysine is negatively charged and can readily interact with various positively charged proteins. ${ }^{21}$ Therefore, the positively charged C-terminus of the lactoferrin protein might bind to the polyL-lysine, thereby reducing the permeability of the secreted 
A.

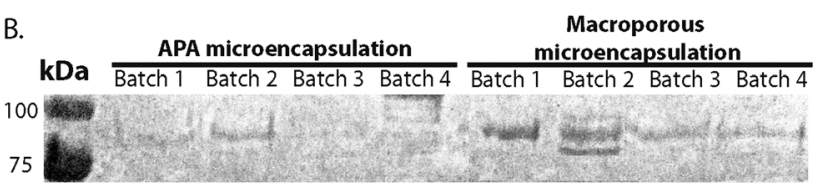

C.

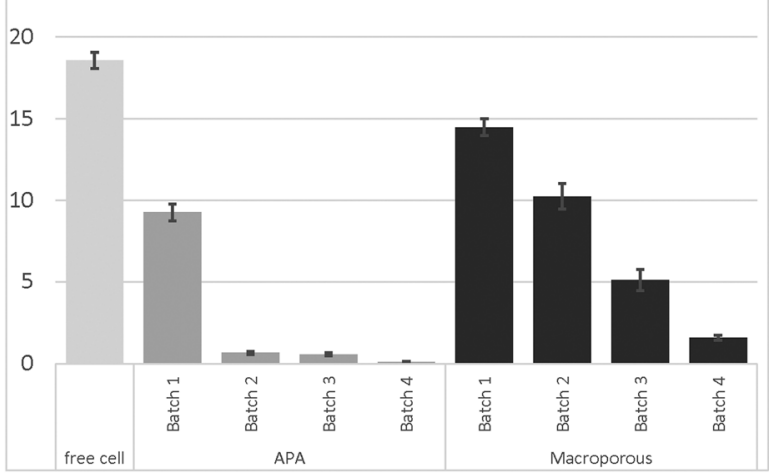

D.

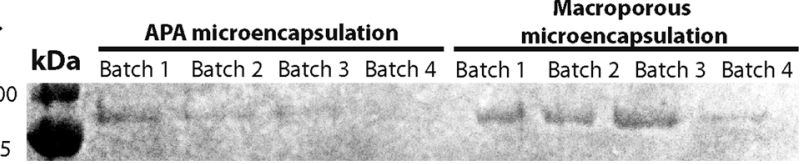

Fig. 2 A. Lactoferrin batch production of galactose inducible protein expression using microencapsulation techniques. B. Secreted lactoferrin expressed using galactose induced APA and macroporous microencapsulation. C. Lactoferrin batch production of TEF constitutive protein expression using microencapsulation techniques. D. Secreted lactoferrin expressed using APA and macroporous microencapsulation.

protein and limiting the production rate. Comparatively, the average pore size of the APA microencapsulated matrix is about $0.2 \mu \mathrm{m},{ }^{22}$ whereas the macroporous microencapsulation matrix has an average pore size of $0.8 \mu \mathrm{m} .^{22 a}$ These matrices are able to retain yeast cells $(\sim 5-15 \mu \mathrm{m}$ in diameter) whilst allowing effective exchange of media and secreted $\mathrm{hLF}^{23}$ Thus, these results suggest that the macroporous microencapsulation is a better alternative for immobilized yeast cell-based protein expression.

In order to ensure that the purified lactoferrin is active, we tested the purified hLF against a wide range of human cancer cell lines such as gastric cancer cell AGS, colorectal cells LoVo, HCT116, and CT26 and breast cancer cell MCF7. Fig. 3 shows that the anti-cancer properties of the purified hLF were relatively high, in which the cancer cells were fully

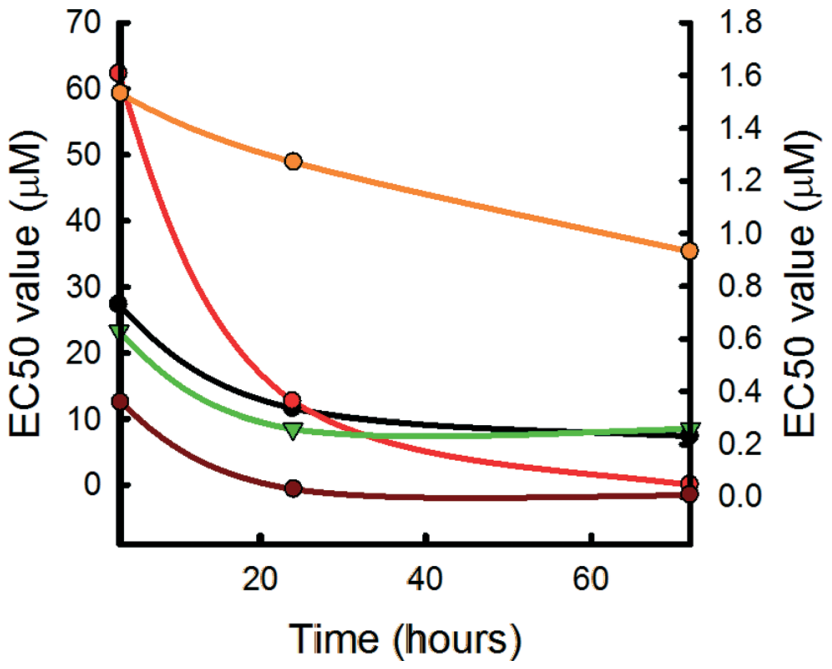

Fig. 3 Anti-cancer inhibition curves of lactoferrin against breast, gastric and colorectal cancer cell lines. The EC50 values within the micro-molar range (reference to the left scale bar) are breast cancer cell line MCF7 (-)), gastric cancer cell line AGS (-) and colorectal cancer cell line LoVo $(-\nabla)$. The EC50 values within the sub-micromolar range (in reference to the right scale bar) are colorectal cancer cell line CT26 (- - ) and colorectal cancer cell line HCT116 (-o-). For the original plots, please refer to the ESI, $\uparrow$ Fig. S2.

inhibited within 24 hours of treatment. The efficacy of the purified hLF was reflected by low half maximal effective concentration (EC50) values, which were below $10 \mu \mathrm{M}$ in the colorectal cell lines tested, whilst gastric cancer cell AGS gave an EC50 value below $60 \mu \mathrm{M}$. This result is consistent with the previous work reporting about $64 \mu \mathrm{M}$ as an EC50 value of bovine lactoferrin, which induced cancer cell apoptosis. ${ }^{24}$ The purified hLF assay against the breast cancer cell line MCF7 resulted in EC50 values below $30 \mu \mathrm{M}$, similar to the results obtained by the use of the lactoferrin homologous protein ovotransferrin. ${ }^{25}$ The anti-cancer properties of hLF results from the prevention of angiogenesis by VEGF inhibition in tissue ${ }^{26}$ the blocking process of the tumor cell cycle at the $\mathrm{G} 1$ to $\mathrm{S}$ phase, ${ }^{1 c}$ and the modulation and stimulation of the production of anti-carcinogenic cytokines such as IL-18, thus causing cancer cell apoptosis. ${ }^{1 b}$

Next, we examined the antibacterial activity of the purified lactoferrin. We evaluated the antibacterial activity of hLF against Gram-positive bacteria (Bacillus subtilis and Staphylococcus aureus) and Gram-negative bacteria (Pseudomonas aeruginosa PAO1, Escherichia coli DH10B and EcN) (Table 1). The purified hLF showed bacteriostatic activity that impedes the overall growth of bacterial cells. This is the result of hLF sequestering ferric ions in the medium that is essential for bacterial growth. The half maximal inhibitory concentration (IC50) values of the purified lactoferrin against the aforementioned microbes are within a micro-molar to sub-micro-molar range (Table 1). The evaluation of the anti-bacterial properties suggested that the purified hLF is a bacteriostatic inhibitor that shows similar values reported by Ulvatne $e t$ al. and Flores-Villasensor et al. ${ }^{27-29}$ 
Table 1 Anti-bacterial screening of purified hLF against various Grampositive and Gram-negative bacteria. For the original plots, please refer to the ESI, Fig. S3

\begin{tabular}{llll}
\hline Bacterial strain & $\begin{array}{l}\text { Measured IC50 } \\
(\mu \mathrm{M})\end{array}$ & $\begin{array}{l}\text { The literature reported } \\
\text { IC50 }(\mu \mathrm{M})\end{array}$ & Ref. \\
\hline $\begin{array}{l}\text { B. subtilis } \text { F2 } \\
\text { S. aureus }\end{array}$ & 0.083 & 0.130 & 28 \\
$\begin{array}{l}\text { NR4220 } \\
\begin{array}{l}\text { P. aeruginosa } \\
\text { PAO1 }\end{array}\end{array}$ & 1.667 & 1.500 & 29 \\
$\begin{array}{l}\text { E. coli } \text { DH10B } \\
\text { E. coli } \text { EcN }\end{array}$ & 0.567 & 1.200 & 29 \\
& 1.209 & 5.000 & 28 \\
& & 5.000 & 28
\end{tabular}

Taken together, our results suggest the following. First, the expressed and purified lactoferrin using the macroporous microencapsulation technique is active, validated by both anti-cancer and anti-bacterial properties. Second, this encapsulation technique can be employed for large-scale protein expression. The immobilization matrix maintains a high copy plasmid count in the host cell by limiting cellular division, circumventing the need for a selection marker.

\section{Experimental section}

\section{Materials}

The human lactoferrin (hLF) gene was codon-optimized and chemically synthesized for Saccharomyces cerevisiae expression with an attached C-terminus 6-Histag sequence (GeneArt). The inducible and constitutive expression shuttle vectors pGAL-MF and pTEF-MF were acquired from Dualsystems Biotech AG. The yeast Saccharomyces cerevisiae BY4741 and bacterial strains were acquired from ATCC. Cancer cell lines were acquired as a gift from Dr. Khoon Lin Ling from the Singapore General Hospital. Media, chemicals and consumables were acquired from Sigma-Aldrich, Difco, Sartorius and Nalgene.

\section{Cloning and expression}

The hLF gene was cloned in both pGAL-MF and PTEF-MF vectors. These constructs were then transformed by lithium acetate-mediated yeast transformation. The cells were then selected by means of URA-minimal SC medium. Positive transformants were seeded into URA-minimal SC medium prior to inoculation into YE medium at $\mathrm{OD}_{600}$ of 0.2. Expression of hLF was conducted by incubating the cells at $30{ }^{\circ} \mathrm{C}$ for 48 hours followed by incubation at $16{ }^{\circ} \mathrm{C}$ for 24 hours. The cell culture was harvested and purified by 6-Histag pulldown. The purified protein buffer was exchanged with a Tris buffer (50 mM Tris-HCl, $300 \mathrm{mM} \mathrm{NaCl,} \mathrm{10 \%} \mathrm{glycerol,}$ $\mathrm{pH}$ 8.0) and stored for the following assays. Protein quantification was performed using a Bradford protein assay. The protein multimeric form was quantified by size exclusion chromatography, which was compared with standards.

\section{Immobilization matrix}

Transformed yeast cells were grown in selective minimal media at about $\mathrm{OD}_{600}$ of 2.0, spun down and washed with sterile PBS twice prior to immobilization. The cell density to volume of immobilizing matrices is approximately $6 \times 10^{7}$ cells $\mathrm{mL}^{-1}$ of the immobilizing reagent. Alginate-poly-L-lysinealginate (APA) immobilization was prepared by re-suspending the cells in sterile ice-cold $0.9 \%$ sodium chloride solution with $2.0 \%$ sodium alginate. The mixture was passed through a 23G syringe needle and dropped into ice-cold $1.4 \%$ calcium chloride, which was stirred continuously for 15 minutes to allow the droplets to gel completely. The resin was then aseptically filtered and collected before re-suspension in $0.05 \%$ poly-L-lysine in a $1 \mathrm{M}$ HEPES buffer, $\mathrm{pH} 7.2$ for 10 minutes. The resin was filtered out and rinsed twice with a sterile $1 \mathrm{M}$ HEPES buffer followed by another coat of $0.1 \%$ sodium alginate for 4 to 8 minutes. The recoated resin was washed with a 1 M HEPES buffer and introduced to fresh media. This will produce beads with an average diameter of $2 \mathrm{~mm}$. Macroporous microencapsulation immobilization was conducted by re-suspending the yeast cells in $3 \mathrm{~mL}$ of $0.9 \%$ sodium chloride solution, followed by introduction under drop-by-drop stirring into $27 \mathrm{~mL}$ of $2 \%$ agarose and $2 \%$ sodium alginate solution. The solution is maintained at a constant temperature of 45$50{ }^{\circ} \mathrm{C}$ to prevent premature gelling. The mixture was expelled through a $23 \mathrm{G}$ syringe needle into stirred ice-cold $2 \%$ calcium chloride solution to give beads with a general diameter of about $2 \mathrm{~mm}$. The resin was then filtered out and rinsed twice with a $1 \mathrm{M}$ HEPES buffer to remove the excessive calcium chloride, followed by introduction into fresh media.

\section{Batch-culturing of immobilized cells}

The resin was then grown in $400 \mathrm{~mL}$ YP medium with an inducer ( $2 \%$ galactose, $1 \%$ raffinose) for pGAL-MF cells or without an inducer ( $2 \%$ raffinose, $1 \%$ glucose) for pTEF-MF cells. These immobilized cells were incubated in the medium under aerated incubation for 2 days at $30^{\circ} \mathrm{C}$. The culture was harvested and secreted hLF was purified using the methods mentioned above. The wet weight of the resin acquired was measured aseptically and introduced into the fresh culture to facilitate protein expression. The batch-culturing was repeated until the amount of protein yield was below $25 \%$ of the initial amount produced.

\section{Anti-cancer assay}

The LoVo cancer cell lines were maintained in Ham's F12 medium supplemented with $10 \%$ fetal bovine serum and penicillin-streptomycin. The other cell lines, CT26, HCT116, MCF7 and AGS, were maintained in DMEM medium supplemented with $10 \%$ fetal bovine serum and penicillinstreptomycin. The cancer cells were seeded into 96 well plates at a concentration of $10^{5}$ cells $\mathrm{mL}^{-1}$ and allowed to grow until $80 \%$ confluency. The cancer cells were then washed twice with a $1 \times$ saline phosphate buffer and introduced to the respective media supplemented with lactoferrin at a concentration range of $5 \mathrm{nM}$ to $100 \mu \mathrm{M}$. The culture was assayed for cell viability using an MTT assay after 3, 24 and 72 hours of incubation. 


\section{Anti-bacterial assay}

The anti-bacterial assay was performed by growing bacterial cultures at an absorbance of $0.2\left(\mathrm{OD}_{600}\right)$ from an overnight culture grown at $37{ }^{\circ} \mathrm{C}, 225 \mathrm{rpm}$. The bacterial culture was then added at a $1: 1$ ratio to a range of lactoferrin from $5 \mathrm{nM}$ to $10 \mu \mathrm{M}$ and measured for bacterial growth at $\mathrm{OD}_{600}$ over time at $37{ }^{\circ} \mathrm{C}$ with constant shaking. The exponential growth slope was measured for inhibitory curve fitting.

\section{Conclusions}

In conclusion, we showed the highest titer reported to date for recombinant hLF production in Saccharomyces cerevisiae, which is close to a 9-fold increase from the previous value. Macroporous microencapsulation was employed to maintain the number of expression host cells whilst giving an efficient nutrient and metabolite exchange. The expression of protein using this method is applicable for both inducible and constitutive expression systems. Both constitutive and induced expression systems can be used for large-scale batch culture bioreactor expression to produce lactoferrin because the immobilized yeast resin is able to facilitate expression up to 3 batch cycles.

\section{Acknowledgements}

We would like to acknowledge the Nutrition and Food Science Grant of the Agency for Science, Technology and Research of Singapore (A*STAR) (112 177 0040). We would like to thank Jiann Guo Yapp, Seok Hwan Lim and Marabeth Xin Yi Kwah from the National University of Singapore High School for their assistance in the experiments.

\section{Notes and references}

1 (a) T. Siqueiros-Cendon, S. Arevalo-Gallegos, B. F. IglesiasFigueroa, I. A. Garcia-Montoya, J. Salazar-Martinez and Q. Rascon-Cruz, Immunomodulatory effects of lactoferrin, Acta Pharmacol. Sin., 2014, 35(5), 557-566; (b) N. D. Embleton, J. E. Berrington, W. McGuire, C. J. Stewart and S. P. Cummings, Lactoferrin: Antimicrobial activity and therapeutic potential, Semin. Fetal Neonatal Med., 2013, 18(3), 143-149; (c) D. Legrand, A. Pierce, E. Elass, M. Carpentier, C. Mariller and J. Mazurier, Lactoferrin structure and functions, Adv. Exp. Med. Biol., 2008, 606, 163-194.

2 G. de la Rosa, D. Yang, P. Tewary, A. Varadhachary and J. J. Oppenheim, Lactoferrin acts as an alarmin to promote the recruitment and activation of APCs and antigen-specific immune responses, J. Immunol., 2008, 180(10), 6868-6876.

3 A. Tursi, W. Elisei, G. Brandimarte, G. M. Giorgetti, M. E. Modeo and F. Aiello, Effect of lactoferrin supplementation on the effectiveness and tolerability of a 7-day quadruple therapy after failure of a first attempt to cure Helicobacter pylori infection, Med. Sci. Monit., 2007, 13(4), CR187-90.

4 (a) H. Saito, M. Takase, Y. Tamura, S. Shimamura and M. Tomita, Physicochemical and Antibacterial Properties of
Lactoferrin and its Hydrolysate Produced by Heat Treatment at Acidic pH, in Lactoferrin, ed. T. W. Hutchens, S. Rumball and B. Lönnerdal, Springer, US, 1994, vol. 357, pp. 219-226; (b) J. L. Gifford, H. N. Hunter and H. J. Vogel, Lactoferricin: a lactoferrin-derived peptide with antimicrobial, antiviral, antitumor and immunological properties, Cell. Mol. Life Sci., 2005, 62(22), 2588-2598.

5 M. Sinha, S. Kaushik, P. Kaur, S. Sharma and T. P. Singh, Antimicrobial lactoferrin peptides: the hidden players in the protective function of a multifunctional protein, Int. J. Pept., 2013, 2013, 390230.

6 (a) T. Suzuki, K. Yamauchi, K. Kawase, M. Tomita, I. Kiyosawa and S. Okonogi, Properties of Peptic-Tryptic Digestion Products of Human and Bovine Lactoferrins, Nippon Eiyo - Shokuryo Gakkaishi, 1989, 42(1), 13-19; (b) K. S. Hoek, J. M. Milne, P. A. Grieve, D. A. Dionysius and R. Smith, Antibacterial activity in bovine lactoferrin-derived peptides, Antimicrob. Agents Chemother., 1997, 41(1), 54-59; (c) F. Ebrahim, J. S. Shankaranarayanan, J. R. Kanwar, S. Gurudevan, U. M. Krishnan and R. K. Kanwar, Identification of Unprecedented Anticancer Properties of High Molecular Weight Biomacromolecular Complex Containing Bovine Lactoferrin (HMW-bLf), PLoS One, 2014, 9(9), e106568; (d) J. Nuijens, P. C. van Berkel and F. Schanbacher, Structure and biological actions of lactoferrin, J. Mammary Gland Biol. Neoplasia, 1996, 1(3), 285-295.

7 P. Valenti, P. Visca, G. Antonini and N. Orsi, Interaction between lactoferrin and ovotransferrin and Candida cells, FEMS Microbiol. Lett., 1986, 33(2-3), 271-275.

8 M. Pammi and S. A. Abrams, Oral lactoferrin for the prevention of sepsis and necrotizing enterocolitis in preterm infants, Cochrane Database Syst. Rev., 2011(10), CD007137.

9 B. L. Waarts, O. J. Aneke, J. M. Smit, K. Kimata, R. Bittman, D. K. Meijer and J. Wilschut, Antiviral activity of human lactoferrin: inhibition of alphavirus interaction with heparan sulfate, Virology, 2005, 333(2), 284-292.

10 C. Nappi, G. A. Tommaselli, I. Morra, M. Massaro, C. Formisano and C. Di Carlo, Efficacy and tolerability of oral bovine lactoferrin compared to ferrous sulfate in pregnant women with iron deficiency anemia: a prospective controlled randomized study, Acta Obstet. Gynecol. Scand., 2009, 88(9), 1031-1035.

11 I. A. García-Montoya, T. S. Cendón, S. Arévalo-Gallegos and Q. Rascón-Cruz, Lactoferrin a multiple bioactive protein: An overview, Biochim. Biophys. Acta, Gen. Subj., 2012, 1820(3), 226-236.

12 A. I. Yemets, I. V. Tanasienko, Y. A. Krasylenko and Y. B. Blume, Plant-based biopharming of recombinant human lactoferrin, Cell Biol. Int., 2014, 38(9), 989-1002.

13 G. Ying, S. H. Wu, J. Wang, X. D. Zhao, J. M. Chen, X. G. Zhang and Y. D. Hou, Producing human lactoferrin by highdensity fermentation recombinant Pichia pastoris, Zhonghua Shiyan He Linchuang Bingduxue Zazhi, 2004, 18(2), 181-185.

14 Z.-G. Tian, D. Teng, Y.-L. Yang, J. Luo, X.-J. Feng, Y. Fan, F. Zhang and J.-H. Wang, Multimerization and fusion expression of bovine lactoferricin derivative LfcinB15-W4,10 
in Escherichia coli, Appl. Microbiol. Biotechnol., 2007, 75(1), 117-124.

15 V. Breguet, R. Gugerli, U. von Stockar and I. Marison, CHO immobilization in alginate/poly-L-lysine microcapsules: an understanding of potential and limitations, Cytotechnology, 2007, 53(1-3), 81-93.

16 B. Sayyar, M. Dodd, J. Wen, S. Ma, L. Marquez-Curtis, A. Janowska-Wieczorek and G. Hortelano, Encapsulation of factor IX-engineered mesenchymal stem cells in fibrinogenalginate microcapsules enhances their viability and transgene secretion, J. Tissue Eng., 2012, 3(1), 2041731412462018.

17 Z. H. Hu, S. Z. Chen, Y. Jin, Y. Xiong, W. Wang, X. J. Ma and M. Song, Microencapsulated nerve growth factor-expressing NIH3T3 cells-incorporated tissue engineering skin: a preliminary study, Singapore Med. J., 2006, 47(6), 504-511.

18 D. Dufrane and P. Gianello, Macro- or microencapsulation of pig islets to cure type 1 diabetes, World J. Gastroenterol., 2012, 18(47), 6885-6893.

19 D. Mattanovich, P. Branduardi, L. Dato, B. Gasser, M. Sauer and D. Porro, Recombinant Protein Production in Yeasts, in Recombinant Gene Expression, ed. A. Lorence, Humana Press, 2012, vol. 824, pp. 329-358.

20 R. Ye, H. Xu, C. Wan, S. Peng, L. Wang, H. Xu, Z. P. Aguilar, Y. Xiong, Z. Zeng and $\mathrm{H}$. Wei, Antibacterial activity and mechanism of action of $\varepsilon$-poly-L-lysine, Biochem. Biophys. Res. Commun., 2013, 439(1), 148-153.

21 M. Gatica, C. C. Allende, M. Antonelli and J. E. Allende, Polylysine-containing peptides, including the carboxylterminal segment of the human c-Ki-ras 2 protein, affect the activity of some key membrane enzymes, Proc. Natl. Acad. Sci. U. S. A., 1987, 84(2), 324-328.

22 (a) L. Gasperini, J. F. Mano and R. L. Reis, Natural polymers for the microencapsulation of cells, 2014, vol. 11; (b) A. Martinsen, G. Skjåk-Bræk and O. Smidsrød, Alginate as immobilization material: I. Correlation between chemical and physical properties of alginate gel beads, Biotechnol. Bioeng., 1989, 33(1), 79-89.

23 (a) D. E. Awrey, M. Tse, G. Hortelano and P. L. Chang, Permeability of alginate microcapsules to secretory recombinant gene products, Biotechnol. Bioeng., 1996, 52(4), 472-484; (b) B. Kulseng, B. Thu, T. Espevik and G. SkjakBraek, Alginate polylysine microcapsules as immune barrier: permeability of cytokines and immunoglobulins over the capsule membrane, Cell Transplant., 1997, 6(4), 387-394.

24 W. R. Pan, P. W. Chen, Y. L. S. Chen, H. C. Hsu, C. C. Lin and W. J. Chen, Bovine lactoferricin B induces apoptosis of human gastric cancer cell line AGS by inhibition of autophagy at a late stage, J. Dairy Sci., 2013, 96(12), 7511-7520.

25 S. H. Moon, J. H. Lee, Y. J. Lee, K. H. Chang, J. Y. Paik, D. U. Ahn and H. D. Paik, Screening for cytotoxic activity of ovotransferrin and its enzyme hydrolysates, Poult. Sci., 2013, 92(2), 424-434.

26 K. Norrby, I. Mattsby-Baltzer, M. Innocenti and S. Tuneberg, Orally administered bovine lactoferrin systemically inhibits VEGF(165)-mediated angiogenesis in the rat, Int. J. Cancer, 2001, 91(2), 236-240.

27 S. Farnaud and R. W. Evans, Lactoferrin - a multifunctional protein with antimicrobial properties, Mol. Immunol., 2003, 40(7), 395-405.

28 H. Ulvatne, O. Samuelsen, H. H. Haukland, M. Kramer and L. H. Vorland, Lactoferricin B inhibits bacterial macromolecular synthesis in Escherichia coli and Bacillus subtilis, FEMS Microbiol. Lett., 2004, 237(2), 377-384.

29 H. Flores-Villasenor, A. Canizalez-Roman, M. Reyes-Lopez, K. Nazmi, M. de la Garza, J. Zazueta-Beltran, N. Leon-Sicairos and J. G. Bolscher, Bactericidal effect of bovine lactoferrin, LFcin, LFampin and LFchimera on antibiotic-resistant Staphylococcus aureus and Escherichia coli, BioMetals, 2010, 23(3), 569-578. 